\title{
Kalirin-7 Mediates Cocaine-Induced AMPA Receptor and Spine Plasticity, Enabling Incentive Sensitization
}

\author{
Xiaoting Wang, ${ }^{1}$ Michael E. Cahill, ${ }^{3}$ Craig T. Werner, ${ }^{1}$ Daniel J. Christoffel, ${ }^{4}$ Sam A. Golden, ${ }^{4}$ Zhong Xie, ${ }^{3}$ \\ Jessica A. Loweth, ${ }^{1}$ Michela Marinelli, ${ }^{2}$ Scott J. Russo, ${ }^{4}$ Peter Penzes, ${ }^{3}$ and Marina E. Wolf ${ }^{1}$ \\ ${ }^{1}$ Department of Neuroscience and ${ }^{2}$ Department of Cellular and Molecular Pharmacology, The Chicago Medical School at Rosalind Franklin University of \\ Medicine and Science, North Chicago, Illinois 60064, ${ }^{3}$ Department of Physiology, Northwestern University Feinberg School of Medicine, Chicago, Illinois \\ 60611, and ${ }^{4}$ Fishberg Department of Neuroscience, Mount Sinai School of Medicine, New York, New York 10029
}

It is well established that behavioral sensitization to cocaine is accompanied by increased spine density and AMPA receptor (AMPAR) transmission in the nucleus accumbens (NAc), but two major questions remain unanswered. Are these adaptations mechanistically coupled? And, given that they can be dissociated from locomotor sensitization, what is their functional significance? We tested the hypothesis that the guanine-nucleotide exchange factor Kalirin-7 (Kal-7) couples cocaine-induced AMPAR and spine upregulation and that these adaptations underlie sensitization of cocaine's incentive-motivational properties-the properties that make it "wanted." Rats received eight daily injections of saline or cocaine. On withdrawal day 14, we found that Kal-7 levels and activation of its downstream effectors Rac-1 and PAK were increased in the NAc of cocaine-sensitized rats. Furthermore, AMPAR surface expression and spine density were increased, as expected. To determine whether these changes require Kal-7, a lentiviral vector expressing Kal-7 shRNA was injected into the NAc core before cocaine exposure. Knocking down Kal-7 abolished the AMPAR and spine upregulation normally seen during cocaine withdrawal. Despite the absence of these adaptations, rats with reduced Kal-7 levels developed locomotor sensitization. However, incentive sensitization, which was assessed by how rapidly rats learned to self-administer a threshold dose of cocaine, was severely impaired. These results identify a signaling pathway coordinating AMPAR and spine upregulation during cocaine withdrawal, demonstrate that locomotor and incentive sensitization involve divergent mechanisms, and link enhanced excitatory transmission in the NAc to incentive sensitization.

\section{Introduction}

Repeated cocaine exposure leads to a progressive and persistent increase in behavioral responses to cocaine termed behavioral sensitization. Most studies measure sensitization of cocaine's psychomotor-activating effects, reflected as enhanced locomotion and/or stereotyped behavior (referred to hereafter as locomotor sensitization for simplicity and because we measured locomotion in the present study). However, sensitization also

Received Feb. 19, 2013; revised May 22, 2013; accepted May 22, 2013.

Author contributions: X.W. and M.E.W. designed research; X.W., M.E.C., C.T.W., and J.A.L. performed research; Z.X., S.J.R., and P.P. contributed unpublished reagents/analytic tools; X.W., M.E.C., C.T.W., D.J.C., S.A.G., and M.M. analyzed data; X.W., M.M., and M.E.W. wrote the paper.

This work was supported by the National Institute on Drug Abuse and the National Institute of Mental Health of the National Institutes of Health (Grant \#R01DA009621, Grant\#R37DA015835, and Grant\#K05DA029099 to M.E.W., Grant \#MH078064 to P.P., and postdoctoral National Research Service Award Grant \#F32DA030844 to J.A.L.). The content is solely the responsibility of the authors and does not necessarily represent the official views of the National Institutes of Health. We thank Dr. A.W. Lasek for preparing the lentiviral vectors, Drs. D.D. Kiraly and B.A. Eipper for providing Kalirin immunoprecipitation protocols, P.A. Loomis and the Werner Straus Live Cell Imaging Facility for training in confocal microscopy, Dr. W.C. Wong for help with experimental design and statistical analysis, Dr. C.R. Ferrario for comments on the manuscript, and K.A. Ford for help with animal surgery.

M.E.W. owns shares in Grace Laboratories, LLC, and CIS Biotech, Inc., but these companies are unrelated to the present work. The remaining authors declare no competing financial interests.

Correspondence should be addressed to Marina E. Wolf, Department of Neuroscience, Rosalind Franklin University of Medicine and Science, 3333 Green Bay Road, North Chicago, IL 60064-3095. E-mail: marina.wolf@rosalindfranklin.edu.

$X$. Wang's present address: Department of Neurobiology, Duke University, Durham, NC 27710.

DOI:10.1523/JNEUROSCI.1097-13.2013

Copyright $\odot 2013$ the authors $\quad 0270-6474 / 13 / 3311012-11 \$ 15.00 / 0$ occurs to the incentive-motivational properties of cocaine, the properties that make cocaine "wanted." Incentive sensitization may contribute to compulsive drug-seeking in addiction (Robinson and Berridge, 1993, 2008; Vezina, 2004), but little is known about its underlying mechanism.

Many neuroadaptations occur in the nucleus accumbens (NAc) during withdrawal from noncontingent cocaine regimens, leading to locomotor sensitization. Here we focus on two adaptations directly related to excitatory synaptic transmission. First, AMPA receptor (AMPAR) transmission in the NAc is enhanced. Thus, AMPAR levels are increased on the cell surface (Boudreau and Wolf, 2005; Boudreau et al., 2007, 2009; Ferrario et al., 2010; Schierberl et al., 2011) and in synaptic membrane fractions (Ghasemzadeh et al., 2009; Schumann and Yaka, 2009) and AMPAR-mediated synaptic transmission is strengthened (Kourrich et al., 2007). This begins during the first week of withdrawal, persists on withdrawal day (WD) 21 (Wolf and Ferrario, 2010), but dissipates by WD41 (McCutcheon et al., 2011). Second, such regimens increase dendritic spine density in the NAc of adult rodents during the first month of withdrawal (Robinson and Kolb, 1999; Norrholm et al., 2003; Li et al., 2004; Pulipparacharuvil et al., 2008; Russo et al., 2009; Kiraly et al., 2010; LaPlant et al., 2010; Maze et al., 2010; Ren et al., 2010; Brown et al., 2011; Dobi et al., 2011; Martin et al., 2011; Wissman et al., 2011; Dietz et al., 2012; Golden and Russo, 2012; Li et al., 2012; Marie et al., 2012; Zhang et al., 2012). 
The increases in AMPAR levels and spine density described above presumably potentiate excitatory synaptic transmission in the NAc. Because such transmission is critical for motivated behaviors, including drug-seeking (Kalivas and Volkow, 2005), these adaptations are thought to be critical for addiction. However, nothing is known about whether AMPAR and spine plasticity are mechanistically linked in cocaine-sensitized rats. Furthermore, although it is apparent that AMPAR and spine plasticity can be dissociated from locomotor sensitization (Singer et al., 2009; for review, see Russo et al., 2010; Wolf and Ferrario, 2010), their relationship to incentive sensitization is unexplored.

Kalirin-7 (Kal-7), a brain-specific guanine-nucleotide exchange factor (GEF), is a key regulator of spine plasticity and excitatory transmission (Penzes and Jones, 2008; Ma, 2010). In hippocampal neurons, Kal-7 is required for activity-dependent spine enlargement and increased GluAl content in spines (Xie et al., 2007), suggesting Kal-7 as a mechanistic link between structural and functional plasticity. Kal-7 has also been implicated in cocaine-induced spine plasticity (Kiraly et al., 2010). The goal of this study was to determine whether activation of Kal-7 signaling mediates cocaine-induced AMPAR and spine plasticity in the NAc and to test the hypothesis that these adaptations are required for the development of incentive sensitization to cocaine.

\section{Materials and Methods}

Subjects. Adult male Sprague Dawley rats (275-300 g on arrival; Harlan Laboratories) were housed 2-3/cage on a $12 \mathrm{~h}$ light:dark cycle, and acclimated to the colony for $\sim 1$ week before use. Experiments were approved by the Institutional Animal Care and Use Committee of Rosalind Franklin University of Medicine and Science.

Locomotor sensitization. Animals were injected intraperitoneally with saline or cocaine (15 mg/kg; Sigma-Aldrich) on 8 consecutive days in photobeam cages (San Diego Instruments). To assess locomotor activity, horizontal beam breaks were recorded throughout a $40 \mathrm{~min}$ habituation phase and for $90 \mathrm{~min}$ after each injection. In some experiments, a challenge injection of cocaine $(15 \mathrm{mg} / \mathrm{kg})$ was administered on WD14 and activity was recorded.

LP1 preparation. The LP1 fraction was prepared from the NAc of individual rats after $14 \mathrm{~d}$ of withdrawal from the regimen of repeated saline or cocaine injections described above. The NAc dissection consisted primarily of core, although lateral shell was also present. The subcellular fractionation protocol was based on a previous study (Goel et al., 2006). Briefly, each NAc sample was first homogenized in sucrose homogenization buffer consisting of the following: $10 \mathrm{~mm}$ HEPES, $0.32 \mathrm{~m}$ sucrose, 1 $\mathrm{mm} \mathrm{Na}_{3} \mathrm{VO}_{4}, 5 \mathrm{~mm} \mathrm{NaF}, 2 \mathrm{~mm}$ EDTA, and 1:100 protease inhibitor mixture set I (Calbiochem). The homogenate was centrifuged $(800 \times \mathrm{g}$, $\left.10 \mathrm{~min}, 4^{\circ} \mathrm{C}\right)$. The resulting supernatant $(\mathrm{S} 1)$ was centrifuged $(10,000 \times$ $\mathrm{g}, 15 \mathrm{~min}, 4^{\circ} \mathrm{C}$ ) to yield the crude membrane pellet (P2). The P2 pellet was resuspended in sucrose homogenization buffer and then centrifuged $\left(10,000 \times \mathrm{g}, 15 \mathrm{~min}, 4^{\circ} \mathrm{C}\right)$ to yield the washed crude membrane pellet (P2'). Last, P2' was lysed with hypo-osmotic shock in cold 4 mм HEPES and centrifuged $\left(25,000 \times \mathrm{g}, 20 \mathrm{~min}, 4^{\circ} \mathrm{C}\right)$ to yield the final synaptosomal membrane fraction (LP1).

Immunoblotting. Protein samples were heated $\left(95^{\circ} \mathrm{C}, 5 \mathrm{~min}\right)$ in Laemmli sample treatment buffer with $5 \%(\mathrm{v} / \mathrm{v}) \beta$-mercaptoethanol. LP1 samples were loaded $5 \mu \mathrm{g}$ per lane and NAc homogenates were loaded $10 \mu \mathrm{g}$ per lane. Samples were electrophoresed on $4-15 \%$ Bis-Tris gradient gels (catalog \#161-1158; Bio-Rad) for analysis of GluA1 and PAKs, and on 4-20\% Bis-Tris gradient gels (catalog \#161-1159; Bio-Rad) for analysis of Kalirin isoforms. Racl immunoprecipitated samples $(30 \mu \mathrm{g})$ were electrophoresed on $4-20 \%$ Bis-Tris gradient gels. For analysis of $\mathrm{BS}^{3}$ crosslinked proteins, samples were loaded $20 \mu \mathrm{g}$ per lane on $4-15 \%$ Bis-Tris gradient gels. Immunoblotting was performed as described previously (Ferrario et al., 2010; Boudreau et al., 2012) using the following primary antibodies: Kal-spectrin (1:500; catalog \#07-122; Millipore), Kal-7 (1:500; catalog \#18-202-335512; Genway), PAK1/2/3 (1:1000; catalog \#2604;
Cell Signaling Technology), p-PAK1(Thr423)/PAK2(Thr402) (1:1000; catalog \#2601S; Cell Signaling Technology), phosphotyrosine (1:500; catalog \#1400-01; Southern Biotech), phosphothreonine (1:500; catalog \#13-9200; Invitrogen), phosphoserine (1:500; catalog \#61-8100; Invitrogen), GluA1 (1:1000; catalog \#PA1-37776; Thermo Scientific), GluA2 (1:200; catalog \#75-002; University of California-Davis/National Institutes of Health NeuroMab Facility), GluA3 (1:1000; catalog \#3437S; Cell Signaling Technology), and GluA2/3 (1:2000; catalog \#B1506; Millipore). After immunoblotting, the immunoreactivity of each band was quantified using Quantity One analysis software (Bio-Rad) and normalized to either total protein in the lane (determined by staining with Ponceau S; catalog \#P7170-1L; Sigma-Aldrich) or a loading control (GADPH; catalog \#CB1001; Calbiochem).

Analysis of Kal-7 signaling. For biochemistry, rats were killed on WD14 without a challenge injection. GluA1 and Kal-7 were measured in an LP1 fraction of NAc prepared as described above. PAKs and Racl were assessed in NAc homogenates. A Racl activation assay kit (catalog \#80501; New East Biosciences) was used to pull down active Rac1, which was then detected by immunoblotting with Rac1 antibody included in the kit (1: 1000). To measure Kal-7 phosphorylation, Kal-7 was immunoprecipitated as described previously (Kiraly et al., 2011b). The starting material was $0.4-0.5 \mathrm{mg}$ of total NAc protein from each rat on WD14 after the cocaine sensitization regimen. To solubilize Kal-7, lysates were prepared using boiling SDS, followed by addition of NP-40 to achieve an NP-40/ SDS weight ratio of 7.5:1. Kal-7 protein was immunoprecipitated using antibody specific for the C terminus of Kal-7 (catalog \#18-202-335512; Genway). Each sample of lysate was mixed with $6 \mu \mathrm{l}$ of antibody and 30 $\mu l$ of Pierce protein A/G agarose beads (catalog \#20421; Thermo Scientific). The final yield of bound fraction from each sample was $\sim 60 \mu$ l. Fifty microliters of each bound fraction was loaded on 4-20\% Bis-Tris gradient gels (catalog \#161-1159; Bio-Rad) and further processed for immunoblotting.

Immunohistochemistry. A previously described Kal shRNA (Xie et al., 2007) was cloned into a pLL3.7 lentiviral vector that expresses GFP (Lasek et al., 2007). Rats received intra-NAc core infusions ( $2 \mu \mathrm{l} /$ side) of this construct (termed shKal) or pLL3.7 vector (termed GFP). Knockdown $(\sim 50 \%)$ was confirmed with immunohistochemistry. Two and 4 weeks after viral injection, coronal NAc sections $(12 \mu \mathrm{m})$ were mounted on gelatin-coated slides. Sections were blocked in PBS containing 5\% $(\mathrm{v} / \mathrm{v})$ goat serum for $1 \mathrm{~h}$ at room temperature. Sections were then incubated with Kal-spectrin antibody (1:200; catalog \#07-122; Millipore) at $4^{\circ} \mathrm{C}$ for $72 \mathrm{~h}$. A biotinylated goat anti-rabbit antibody (1:250; catalog \#BA-1000; Vector Laboratories) was incubated with the sections for 90 min after washing off primary antibody. Last, sections were treated with Alexa Fluor 594-conjugated streptavidin (1:200; catalog \#S32356; Invitrogen) for $2 \mathrm{~h}$, followed by washing with PBS and $\mathrm{dd}_{2} \mathrm{O}$. Kal staining intensity was measured from images taken with a confocal microscope (Fluoview 300; Olympus).

Stereotaxic surgery for virus injection. Before surgery, rats were anesthetized with a ketamine-xylazine mixture ( 80 and $10 \mathrm{mg} / \mathrm{kg}$, respectively) and placed in a stereotaxic frame. Either GFP or shKal viruses $(2 \mu \mathrm{l}$ per side) were bilaterally microinjected into NAc core $(0.2 \mu$ l per min) using a Hamilton syringe. The coordinates for NAc core were as follows: AP: $+1.2 \mathrm{~mm}$; L: $+2.6 \mathrm{~mm}\left(6^{\circ}\right.$ angle $)$ and DV: $-7.0 \mathrm{~mm}$ (Conrad et al., 2008). Each $2 \mu \mathrm{l}$ microinjection was made over $10 \mathrm{~min}$ and the injectors were left in place for $5 \mathrm{~min}$ after the injection. We targeted the core because robust AMPAR and spine plasticity are observed in this region (Robinson and Kolb, 2004; Ferrario et al., 2005). The placement of each injection was verified at the end of behavioral testing by preparing brain slices and determining the location of GFP expression using a fluorescence microscope (Eclipse C600; Nikon). Only rats that exhibited GFPexpressing cells within the NAc core were included in data analysis.

AMPAR and spine analysis after Kal-7 knock-down. Two weeks after virus injection, rats began the regimen of 8 daily saline or cocaine injections described above. They were decapitated on WD14. For each rat, hemispheres were separated so that one could be used for AMPAR analysis and the other for spine analysis. The hemisphere destined for AMPAR analysis was placed in a brain matrix (ASI Instruments). To immobilize it, the space normally occupied by the other hemisphere was filled with a piece of mezze penne (al dente). A $2 \mathrm{~mm}$ coronal section 
containing the NAc was then obtained. NAc tissue (primarily core) was punched, minced, and incubated $\left(30 \mathrm{~min}, 4^{\circ} \mathrm{C}\right)$ with the membrane impermeant protein crosslinking agent BS $^{3}$ (catalog \#21585; Thermo Scientific). BS $^{3}$ selectively modifies cell surface proteins, increasing their apparent molecular weight and enabling them to be separated from unmodified intracellular proteins by SDS-PAGE/immunoblotting (Boudreau et al., 2012). The other hemisphere was used for spine analysis as described previously (Russo et al., 2009; Christoffel et al., 2011). It was fixed in $2.5 \%(\mathrm{w} / \mathrm{v})$ paraformaldehyde (EMS) overnight, stored in PBS containing $30 \%(\mathrm{w} / \mathrm{v})$ sucrose, and sectioned $(100 \mu \mathrm{m})$ on a Vibratome (Ted Pella). Sections were immunostained using antibody against GFP to better discriminate spines in transfected neurons (1:5000; catalog \#290; Abcam). Distal dendrites, which show robust cocaine-induced plasticity (Robinson and Kolb, 2004; Ferrario et al., 2005), were randomly selected by an experimenter blind to experimental groups. Dendritic segments were imaged on a confocal microscope (LSM 510; Carl Zeiss) using a $100 \times$ oil lens (numerical aperture 1.4) and a zoom of 2.5. Images were taken with a resolution of $1024 \times \sim 300 \mu \mathrm{m}$ ( $y$ dimension was adjusted to the particular dendritic segment), $x-y$ scaling at $0.02 \mu \mathrm{m}$ and a $z$-step at $0.2 \mu \mathrm{m}$. NeuronStudio software (Rodriguez et al., 2008; Dumitriu et al., 2011; http://www.mssm.edu/cnic/downloads/ns0.9.92.zip) was used for quantitative analysis of spine number and shape (3-5 segments/neuron, 5-7 neurons/rat, 5-7 rats per group).

Test for acquisition of cocaine self-administration. Sensitization of the rewarding effects of cocaine can be measured as the ability of cocaine preexposure to increase the rate at which rats learn to self-administer a low dose of cocaine (Horger et al., 1990; Schenk and Partridge, 2000). Although other approaches exist (Mendrek et al., 1998; Lorrain et al., 2000; Wyvell and Berridge, 2001), we adopted this measure of incentive sensitization because it captures the effect of cocaine preexposure on voluntary drug taking and minimizes exposure of our control group (saline-preexposed rats) to cocaine during the self-administration phase. Such exposure could compromise preexisting group differences. Despite these advantages, the rate of acquisition of cocaine self-administration is not a "pure" measure of incentive sensitization and additional studies using more precise approaches (Wyvell and Berridge, 2001) should be performed in the future. For our acquisition experiments, rats received intra-NAc core injections of shKal or GFP lentivirus followed by repeated intraperitoneal injections of cocaine or saline as described above. One week after the last injection (WD7), all rats were implanted with intravenous catheters (Conrad et al., 2008). Allowing 1 week of recovery from surgery, the test for acquisition of cocaine self-administration began on WD14. All rats were given access to cocaine for $2 \mathrm{~h} / \mathrm{d}$ on 10 consecutive days in operant chambers (Med Associates). Nose poking in the active hole delivered an infusion of cocaine $(0.15 \mathrm{mg} / \mathrm{kg}$ per infusion over $3 \mathrm{~s}$, fixed ratio 1) paired with a $5 \mathrm{~s}$ light cue inside the nose-poke hole, followed by a $5 \mathrm{~s}$ time-out period. Nose poking in the inactive hole had no consequences. After the last training session, the patency of the catheter was tested by infusing $10 \mathrm{mg} / \mathrm{kg}$ sodium brevital (Henry Schein). Rats that failed to be anesthetized within seconds were excluded from data analysis.

Test for acquisition of sucrose self-administration. Two weeks after injection of shKal or GFP viruses into the NAc core, a separate group of animals was tested in the same operant chambers used for cocaine selfadministration, but the drug-delivery apparatus was replaced by a sucrose pellet dispenser. All rats were given access to sucrose for $2 \mathrm{~h} / \mathrm{d}$ on 9 consecutive days. Nose poking in the active hole delivered a sucrose pellet paired with a $5 \mathrm{~s}$ light cue inside the nose-poke hole, followed by a $10 \mathrm{~s}$ time-out period. Nose poking in the inactive hole had no consequences. The number of uneaten pellets at the end of each session was subtracted from total pellets delivered before data analysis.

Data analysis. Data from Western blots, Kal immunostaining, and spine analysis were analyzed with unpaired $t$ tests (two-tailed unless otherwise stated). Locomotor activity data were evaluated using repeatedmeasures ANOVA with drug pretreatment as between-subject factors and days as the repeated measure. Post hoc analyses were done with Duncan's tests. In experiments on acquisition of cocaine or sucrose selfadministration, both locomotor activity and self-administration data were analyzed using repeated-measures ANOVA with drug pretreatment

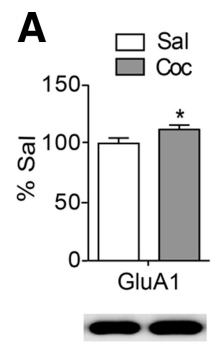

B
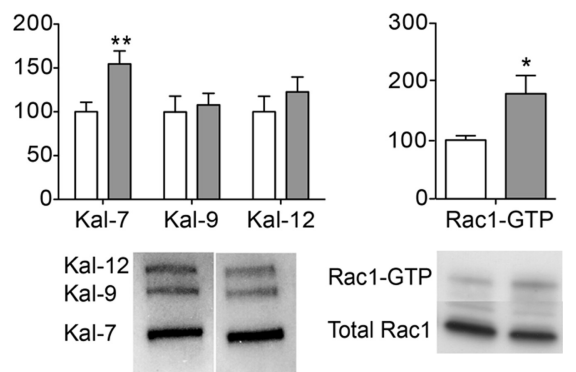

$\Delta$ Kal-7

D
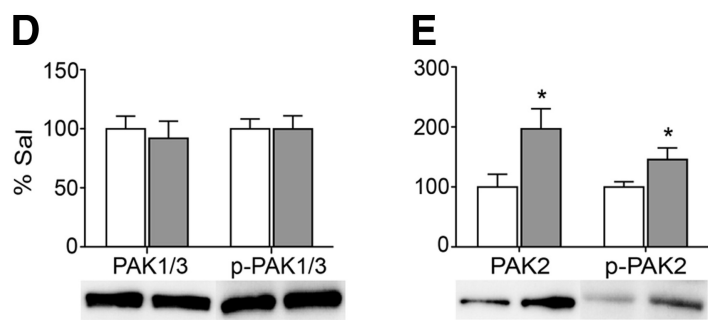

Figure 1. Biochemical analysis of Kal-7 and signaling proteins in the NAc after $14 \mathrm{~d}$ of withdrawal from repeated cocaine injections. Data are expressed as average percent change from saline controls. $\boldsymbol{A}, \boldsymbol{B}$, Significant increases in GluA1 and Kal-7 protein levels were detected in an LP1 fraction from the NAc of cocaine-sensitized rats, but no significant change was found for Kal-9 or Kal-12. GluA1 and Kal isoforms were analyzed in the same LP1 fractions (Sal, $n=11$ rats; $C 0 c, n=11$ rats). $C$, Increased Rac1-GTP was detected in NAc homogenates from cocainesensitized rats ( $S a l, n=8 ; C O C, n=8)$. D, E, Protein levels of PAK2 and PAK2 phosphorylation [p-PAK2 (Thr402)] were increased in NAc homogenates from cocaine-sensitized rats ( $\mathrm{Sal}, n=$ 10; $C o c, n=11)$. Representative bands are shown at the bottom of each panel. Kal-7 was detected by Kal-spectrin antibody recognizing a common sequence among Kalirin isoforms. ${ }^{*} p<0.05,{ }^{* *} p<0.01, t$ tests.

as between-subject factors and days as the repeated measure. Post hoc analyses were done with Duncan's tests. In the figures, $n$ indicates rats/ group unless otherwise indicated, error bars show SEM, and n.s. indicates not significantly different.

\section{Results}

\section{Cocaine increases Kal-7 levels and activates Rac1 and PAK}

To examine the role of Kal-7 in cocaine-induced behavioral sensitization, we compared adult rats injected with cocaine (Coc; 15 $\mathrm{mg} / \mathrm{kg}$, i.p.) or saline (Sal) for 8 consecutive days in photobeam cages. Measurement of locomotor activity on days 1 and 8 in both groups verified that cocaine treatment produced a sensitized locomotor response whereas saline treatment did not [main effect of pretreatment: $F_{(1,22)}=110, p<0.001$; main effect of days: $F_{(1,22)}=19.8, p<0.001$; interaction between pretreatment and days: $F_{(1,22)}=25.7, p<0.001$; therefore, locomotor activity was higher on injection day 8 than day 1 for Coc rats $(p<0.001)$, but not for Sal rats (n.s.); $\operatorname{Coc} n=12$, Sal $n=12$; data not shown]. Rats were killed on WD14, a moderate withdrawal time at which increased AMPAR surface expression and spine density have been observed using the same cocaine regimen (Li et al., 2004; Ferrario et al., 2010).

Kal-7 is localized almost exclusively to the postsynaptic density (Penzes et al., 2000; Mains et al., 2011). Therefore, we prepared a synaptosomal membrane fraction (LP1) to compare GluA1 and Kal-7 levels in the NAc of cocaine- and saline-treated rats. As expected (Wolf and Ferrario, 2010), GluA1 was increased in the cocaine group (Fig. $1 A, t_{(20)}=2.0,{ }^{\star} p<0.05$, one-tailed $t$ test), although the magnitude of the increase was smaller than we have found previously using a $\mathrm{BS}^{3}$ protein crosslinking assay 
(Ferrario et al., 2010; see also Fig. 5). This is probably because the LP1 fraction contains some GluA1 that is membrane associated but not externalized (e.g., GluA1 in trafficking endosomes) whereas the BS $^{3}$ assay selectively detects surface AMPARs. Kal-7 was the most abundant Kal isoform in the adult rat NAc (Fig. 1B), as reported previously in mice (Mains et al., 2011). Only Kal-7, not the other two isoforms (Kal-9 and Kal-12), increased in the cocaine group on WD14 (Fig. $1 B$, Kal-7: $t_{(20)}=2.9,{ }^{* *} p<0.01$; Kal-9: $t_{(20)}=0.3$, n.s.; Kal-12: $t_{(20)}=0.9$, n.s.). Levels of the splice variant $\Delta$ Kal-7 were too low for reliable quantification. These results on WD14 extend prior studies showing that Kal-7 expression is increased $24 \mathrm{~h}$ after cocaine exposure (Kiraly et al., 2010; Mains et al., 2011; see Discussion).

Kal-7 regulates actin cytoskeletal dynamics by activating the small GTPase Rac1 (Penzes et al., 2000). By measuring its active GTP-bound form (Rac1-GTP), we found that Racl activity was markedly increased in NAc homogenates from cocainesensitized rats (Fig. $\left.1 C, t_{(14)}=2.31,{ }^{\star} p<0.05\right)$. PAKs (p21activated kinases) are major substrates of Racl. Binding of activated Racl causes PAK autophosphorylation and activation (Hayashi et al., 2002). We therefore investigated whether chronic cocaine treatment engages the Rac1-PAK pathway by measuring expression and phosphorylation of all three PAK isoforms in NAc homogenates. Although no group difference was observed for PAK1/3 (Fig. 1D; these isoforms could not be resolved), both PAK2 protein levels and PAK2 phosphorylation were increased in cocaine-sensitized animals (Fig. $1 E$, PAK2: $t_{(19)}=2.4,{ }^{\star} p<$ 0.05 ; P-PAK2: $\left.t_{(19)}=2.3,{ }^{\star} p<0.05\right)$. The significance of selective PAK2 activation is unclear because little is known about PAK2's specific role in the brain (Kreis and Barnier, 2009). These results demonstrate increased protein levels of Kal-7 and activation of its downstream effectors Rac1 and PAK2 in the NAc of cocainesensitized rats on WD14.

\section{Kal-7 phosphorylation after cocaine or saline treatment}

Although Kal-7 contains multiple phosphorylation sites (Kiraly et al., 2011b), the functional significance of phosphorylation for Kal-7's GEF activity is unclear (Xie et al., 2007; Kiraly et al., 2011b). To determine whether repeated cocaine injections alter Kal-7 phosphorylation, we immunoprecipitated Kal-7 from the NAc of individual cocaine-treated and saline-treated animals using Kal-7 antibody as described previously (Kiraly et al., 2011b). The majority of Kal-7 protein was successfully pulled down (Fig. 2A). However, in both groups, no phosphorylation signal or only a trace signal was detected on immunoblots by antibodies recognizing phosphorylated tyrosine, serine, or threonine residues (Fig. 2B). It is possible that the phosphorylation level of Kal-7 is below our detection limit and/or that cocaine produces a transient change in Kal-7 phosphorylation not captured on WD14.

\section{Lentiviral delivery of Kal shRNA reduces Kal expression in the NAc}

First, we established an immunostaining protocol using Kalspectrin antibody. Consistent with prior results (Kiraly et al., 2010; Ma et al., 2011, 2012; Mains et al., 2011), abundant Kal staining was observed in hippocampus and NAc of wild-type animals (Fig. 3A, left and center), but was eliminated from Kal knock-out mice (Cahill et al., 2009; Fig. 3A, right). In the NAc, Kal was present in neurons with the morphology of medium spiny neurons, the predominant cell type and output neuron of the NAc (Meredith et al., 2008). To knock down Kal expression, we used a short hairpin RNA (shRNA) shown to decrease Kal-7
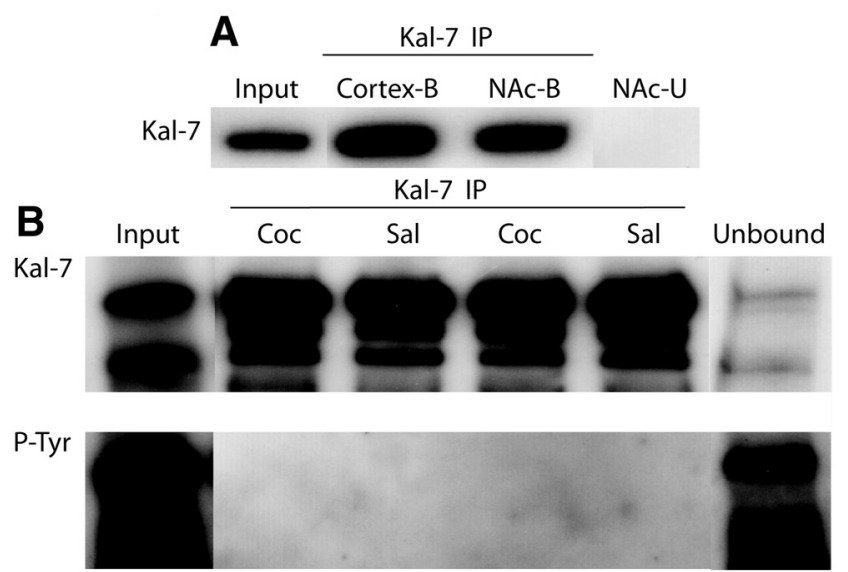

P-Ser
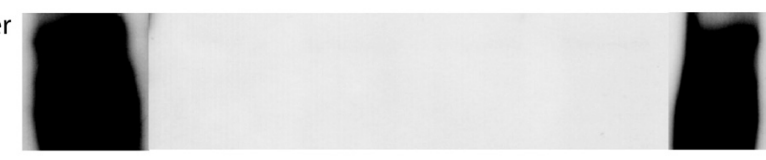

P-Thr
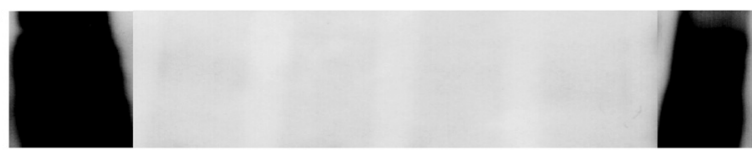

Figure 2. Repeated cocaine injections do not produce detectable changes in the Kal-7 phos phorylation state. To measure phosphorylation of Kal-7, we immunoprecipitated Kal-7 using a Kal-7-specific antibody, as described previously (Kiraly et al., 2011b), and probed with antibodies to phosphorylated tyrosine ( $p$-Tyr), serine ( $p$-Ser), and threonine ( $p$-Thr) residues. $\boldsymbol{A}$, Validation of our immunoprecipitation (IP) procedure based on analysis of cortical and NAc tissue from drug-naive rats ( $B$, bound fraction; $U$, unbound fraction). Robust signals were found in the bound fraction, whereas Kal-7 was below the limit of detection in the NAc unbound fraction (NAC-U). B , To determine whether repeated cocaine injections alter Kal-7 phosphorylation, we immunoprecipitated Kal-7 from the NAc of individual cocaine-treated and saline-treated animals. Although the vast majority of Kal-7 protein was immunoprecipitated by Kal-7-specific antibody under our conditions, as shown in $\boldsymbol{A}$, no phosphorylation signal or only a trace signal was detected on immunoblots by $\mathrm{p}$-Tyr, p-Ser, or p-Thr antibodies. Tissue homogenate (input) and unbound fractions were run on each gel for comparison. Phosphorylation signals were detected in the input and unbound lanes for all three phosphospecific antibodies, providing positive controls.

levels by $50 \%$ and prevent activity-dependent increases in spine size and AMPAR transmission in cultured neurons (Xie et al., 2007). The shRNA was cloned into a pLL3.7 lentiviral vector that expresses GFP. To test the efficiency of Kal knock-down, this viral construct (termed shKal) or pLL3.7 vector (termed GFP) was microinjected into the NAc core of drug-naive rats. Immunostaining showed that Kal expression was reduced by $\sim 50 \%$ in the NAc of rats killed 2 or 4 weeks after injection (Fig. 3C, 2 weeks: $t_{(343)}=8.5,{ }^{* *} p<0.001 ; 4$ weeks: $t_{(148)}=8.3,{ }^{* *} p<0.001$; Fig. $3 D, 2$ weeks: $t_{(254)}=9.1,{ }^{\star *} p<0.001 ; 4$ weeks: $t_{(145)}=12.99$, $\left.{ }^{* * *} p<0.001\right)$.

\section{Kal knock-down prevents cocaine-induced spine plasticity}

To determine whether Kal-7 is required for cocaine-induced increases in spine density, we injected shKal or GFP lentivirus into the NAc core, selecting this subregion because it exhibits robust cocaine-induced AMPAR and spine plasticity (Li et al., 2004; Wolf and Ferrario, 2010). After allowing 2 weeks to achieve stable knock-down (Fig. $3 B-D$ ), rats received 8 daily injections of cocaine or saline, generating GFP/Sal, shKal/Sal, GFP/Coc, and shKal/Coc groups (Fig. 4A). The latter two groups exhibited locomotor sensitization (Fig. $4 F$, main effect of pretreatment: $F_{(3,37)}=12.83, p<0.001 ;$ main effect of days: $F_{(1,37)}=25.02, p<$ 
0.001; interaction between pretreatment and days: $\left.F_{(3,37)}=11.87, p<0.001\right)$. Therefore, locomotor activity was higher on injection day 8 than day 1 for GFP/Coc rats $\left({ }^{* *} p<0.01\right)$ and $s h \mathrm{Kal} / \mathrm{Coc}$ rats $\left({ }^{* *} p<0.001\right)$, but not for GFP/Sal rats $(p=0.51$, n.s. $)$ or $\operatorname{shKal} /$ Sal rats $(p=$ 0.72 , n.s.). Furthermore, GFP/Coc and ShKal/Coc rats showed similar sensitization (main effect of viral treatment: $F_{(1,17)}$ $=1.9$, n.s.; main effect of days: $F_{(1,17)}=$ 23.29, $p<0.001$; interaction between viral treatment and days: $F_{(1,17)}=2.37$, n.s.). Rats were killed on WD14. Brains were rapidly removed and divided into right and left hemispheres. One hemisphere was used for spine analysis. The other was used for AMPAR analysis (see next section). Because we could not simultaneously process all four groups, three experiments using separate cohorts of animals were conducted to compare two groups at a time: (1) GFP/Sal versus GFP/ $\mathrm{Coc}$, (2) GFP/Coc versus shKal/Coc, and (3) GFP/Sal versus shKal/Sal.

By comparing rats that received control virus followed by repeated saline or cocaine injections (GFP/Sal and GFP/Coc groups, respectively), we replicated prior findings of increased total spine density in the NAc of cocaine-sensitized animals (Fig. $4 B, C, t_{(9)}=4.2,{ }^{*} p<0.01$ ). Furthermore, by classifying spines using NeuronStudio, we demonstrated that cocaine increased the density of thin and stubby spines with a trend toward increased density of mushroom spines (Fig. $4 C$, Stubby: $t_{(9)}=$ 2.24, ${ }^{*} p<0.05$; Thin: $t_{(9)}=3.52,{ }^{* *} p<0.01$; Mushroom: $t_{(9)}=1.83, p=0.10$, n.s.). Conversely, the shKal/Coc group showed markedly lower spine density compared with the GFP/Coc group, indicating that Kal knockdown prevented repeated cocaine injections from increasing spine density (Fig. $4 B, D$, Total spines: $t_{(12)}=2.44,{ }^{\star} p<0.05$; Stubby: $t_{(12)}=3.84,{ }^{* *} p<0.01$; Thin: $t_{(12)}=2.39,{ }^{*} p<0.05$; Mushroom: $\left.t_{(12)}=6.60,{ }^{* *} p<0.001\right)$. No significant differences were observed between GFP/Sal and shKal/Sal groups (Fig. 4B,E). Therefore, Kal knock-down prevented the cocaine-induced increase in spine density while having no effect in saline-treated animals.

\section{Kal knock-down prevents}

\section{cocaine-induced AMPAR upregulation}

Based on a role for Kal-7 in AMPAR synaptic delivery in other cell types (Xie et al., 2007; Cahill et al., 2009), we hypothesized that Kal-7 was involved in the cocaine-induced increase in AMPAR surface expression. We tested this by using a protein crosslinking assay (Boudreau et al., 2012) to compare AMPAR subunit surface and intracellular levels in the same experimental groups generated for the spine studies (see previous section).

Focusing first on AMPAR surface expression (Fig. 5B-D), GFP/Coc rats exhibited increased surface GluA1 and GluA2 and a trend toward increased GluA2/3 compared with GFP/Sal rats

\section{A Kalirin immunostaining in naive animals}
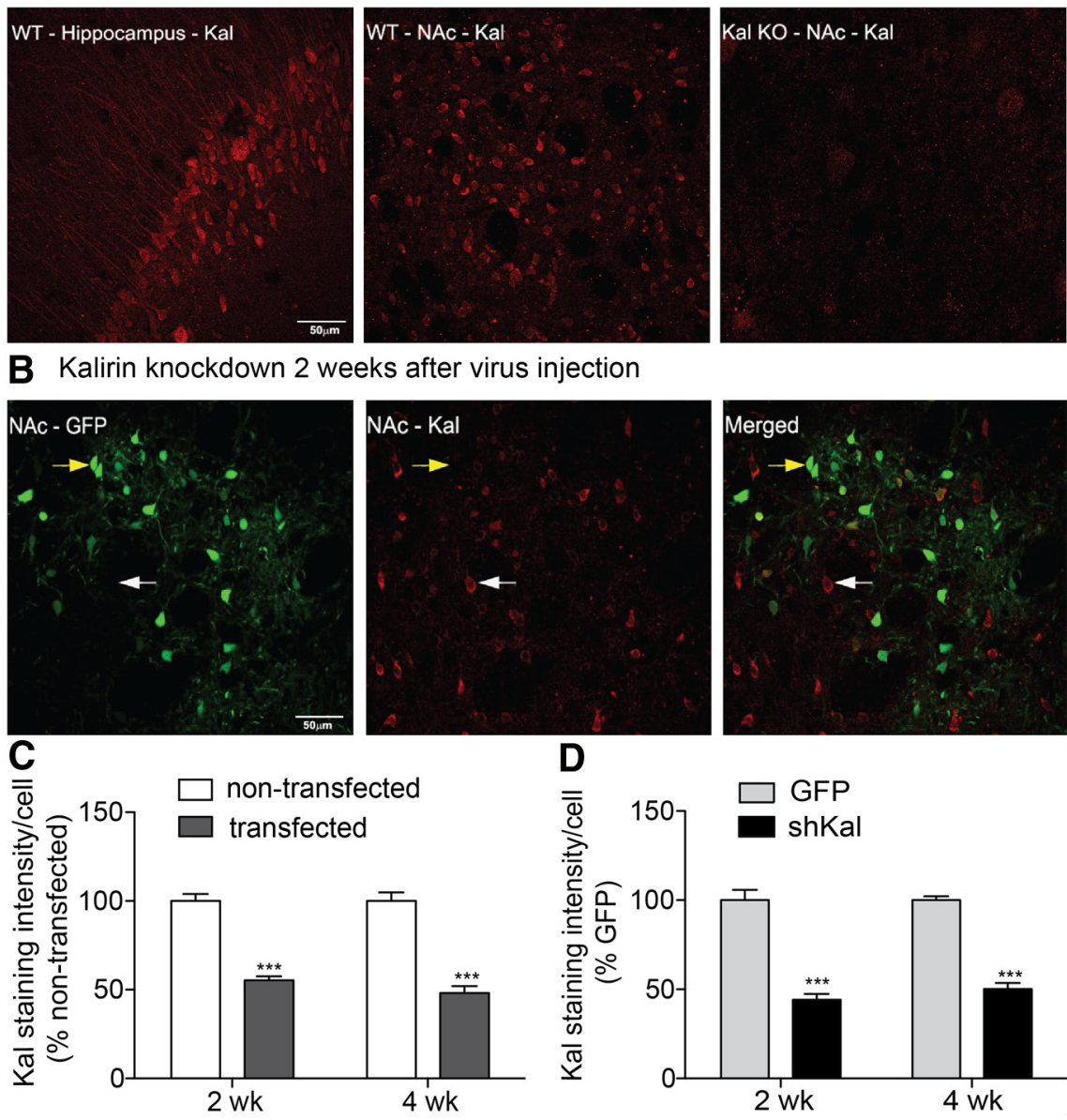

Figure 3. Lentivirus expressing Kal shRNA (shKal) reduces Kal immunostaining in the NAc by $\sim 50 \%$. $A$, We detected robust Kal munostaining in the hippocampus of naive rats (left), moderate staining in the NAc of naive rats (center), and loss of signal in the (be Kal sequence GCAGTACAATCCTGGCCATGT (beginning at , was cloned into a pLL3.7 lentiviral vector that expresses GFP. To determine the efficiency of Kal knock-down, this after virus injection. GFP (left) and Kal staining (center) were visualized (right panel shows merged images). C, Quantification of these results revealed a reduction of $\sim 50 \%$ when comparing transfected (GFP-positive) NAc neurons in shKal rats (yellow arrow) with nontransfected neurons in the same brain section (white arrow; 2 weeks: $n=345$ cells; 4 weeks: $n=150$ cells; ${ }^{* * *} p<$ 0.001). D, A similar reduction in Kal staining was found when comparing transfected (GFP-positive) NAc neurons from shKal rats with transfected neurons from GFP rats ( 2 weeks: $n=256$ cells; 4 weeks: $n=147$ cells; ${ }^{* * *} p<0.001$ ).

(Fig. $5 B$, GluA1: $t_{(17)}=2.32,{ }^{\star} p<0.05$; GluA2: $t_{(17)}=2.50,{ }^{\star} p<$ $0.05)$. This is consistent with prior work showing increased surface or synaptic expression of GluA1A2-containing AMPARs in the NAc of cocaine-sensitized rats (Boudreau and Wolf, 2005; Boudreau et al., 2007, 2009; Kourrich et al., 2007; Ghasemzadeh et al., 2009; Schumann and Yaka, 2009; Ferrario et al., 2010; Schierberl et al., 2011). However, GluA1 surface expression was markedly reduced in shKal/Coc animals compared with GFP/ Coc animals, indicating that Kal knock-down in the NAc prevented the cocaine-induced increase in surface GluA1 (Fig. $5 C$, $\left.t_{(15)}=2.75,{ }^{*} p<0.05\right)$. In addition, the shKal/Coc group showed trends toward reductions in surface GluA2, GluA3, and GluA2A3 (Fig. 5C), consistent with prevention of the upregulation of GluA1-containing AMPARs that also contained GluA2 or GluA3. However, when shKal animals were treated with repeated saline injections, it was GluA2/3 (detected with antibody recognizing both subunits) that showed a decrease in surface expression compared with GFP/Sal animals, whereas surface GluAl did not differ 

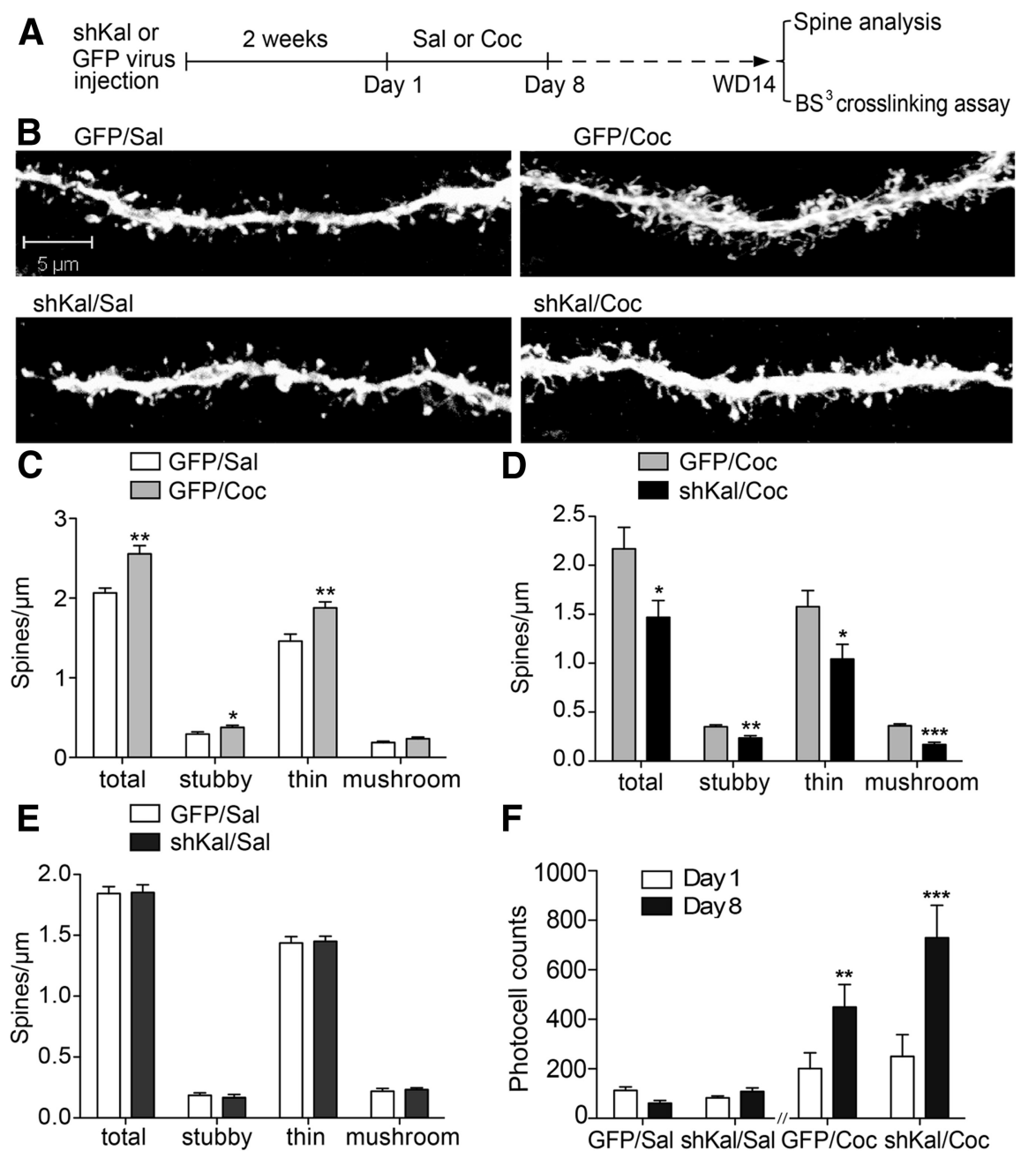

Kal knock-down does not prevent locomotor sensitization

In animals used for studies of spines (Fig. 4) and AMPAR surface expression (Fig. 5), injection of shKal did not prevent locomotor sensitization (Fig. 4F). However, the design of the experiments precluded a test for expression of sensitization after withdrawal. Therefore, we injected additional rats with shKal or GFP virus 3 weeks before beginning repeated cocaine or saline injections and measured locomotor activity on each injection day and in response to cocaine challenge on WD14 (Fig. 6). Both treatment groups developed sensitization to a similar extent, as indicated by a main effect of days (day 1, day 8 , and WD14, $\left.F_{(2,30)}=21.63, p<0.05\right)$ without any effect of viral treatment $\left(F_{(1,15)}=0.03, p=0.86\right.$, n.s. $)$ or interaction between viral treatment and days $\left(F_{(2,30)}=1.43, p=0.25\right.$, n.s. $)$. For GFP/ Coc rats, locomotor activity was higher on injection day 8 than day $1\left({ }^{* *} p<0.01\right)$ and was still elevated when rats were challenged with the same dose of cocaine on WD14 (day 1 vs WD14: ${ }^{* *} p<0.001$; day 8 vs WD14: $p=0.26$, n.s.). Similarly, for shKal/Coc rats, locomotor activity was higher on injection day 8 than day 1 $\left.{ }^{* * *} p<0.001\right)$ and was still elevated when rats were challenged with the same dose of cocaine on WD14 (day 1 vs WD14: ${ }^{* *} p<$ 0.01 ; day 8 vs WD14: $p=0.38$, n.s.). Therefore, Kal knock-down does not prevent either the induction or maintenance of locomotor sensitization, supporting conclusions reached in Kal-7 knock-out mice (Kiraly et al., 2010).

\section{Incentive sensitization is impaired by \\ Kal knock-down}

We took advantage of the cellular effects of Kal knock-down to investigate whether cocaine-induced AMPAR upregulation and spine plasticity are required for incentive sensitization, measured as the ability between these groups (Fig. $5 D, t_{(20)}=3.39,{ }^{* *} p<0.01$ ). We interpret these results in light of a model positing constitutive cycling of GluA2A3 and activity-dependent insertion of GluA1-containing receptors (see Discussion).

Turning to analysis of intracellular AMPAR subunit levels (Fig. $5 E-G$ ), the most remarkable effect was a robust increase in intracellular levels of all three subunits in shKal/Sal animals compared with GFP/Sal animals (Fig. 5G, GluA1: $t_{(20)}=3.98,{ }^{* * *} p<$ 0.001; GluA2: $t_{(20)}=2.63,{ }^{\star} p<0.05$; GluA3: $t_{(20)}=4.05,{ }^{* * *} p<$ 0.001 ), which occurred in the absence of changes in their surface expression (Fig. 5D). Although the mechanisms responsible are unclear, this abnormal accumulation of intracellular AMPARs is consistent with a role for Kal in regulating AMPAR cycling between surface and intracellular pools. We also observed a reduction in intracellular GluA3 levels in GFP/Coc compared with $\mathrm{GFP} / \mathrm{Sal}$ rats $\left(t_{(17)}=2.15,{ }^{*} p<0.05\right)$. of cocaine preexposure to increase the rate at which rats learn to self-administer a low dose of cocaine (Horger et al., 1990; Schenk and Partridge, 2000). Advantages and caveats associated with this measure of incentive sensitization are described in the Materials and Methods.

Four experimental groups were included in this study: GFP/ Sal, GFP/Coc, shKal/Sal, and shKal/Coc. All groups received intra-NAc core virus followed by $8 \mathrm{~d}$ of saline or cocaine injections (Fig. 7A). Both cocaine-injected groups displayed locomotor sensitization (Fig. $7 B$; main effect of pretreatment: $F_{(3,46)}=8.20, p<$ 0.001; main effect of days: $F_{(1,46)}=19.44, p<0.001$; interaction between pretreatment and days: $\left.F_{(3,46)}=6.79, p<0.001\right)$. Therefore, locomotor activity was higher on injection day 8 than day 1 for GFP/Coc rats $\left({ }^{* * *} p<0.01\right)$ and shKal/Coc rats $\left({ }^{* * *} p<0.001\right)$, but not for GFP/Sal rats ( $p=0.84$, n.s. $)$ or shKal/Sal rats $(p=0.84$, n.s. $)$. Furthermore, GFP/Coc and ShKal/Coc rats showed similar sensiti- 

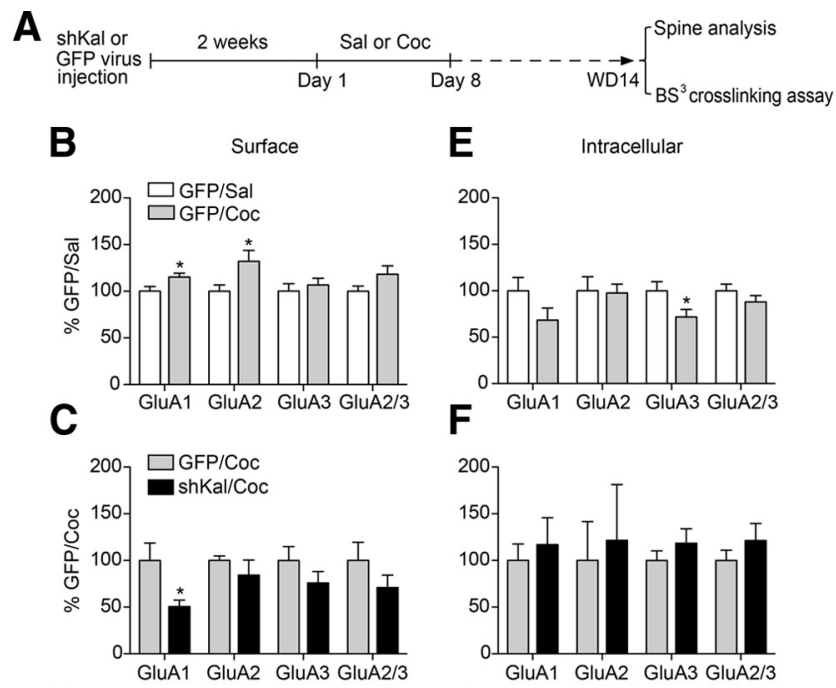

D

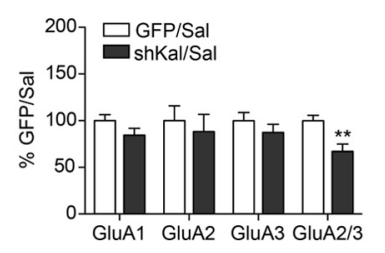

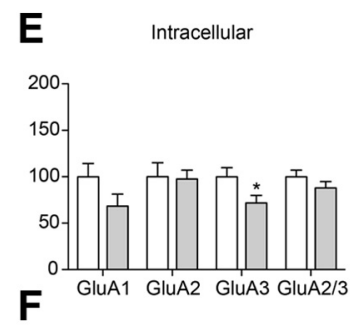

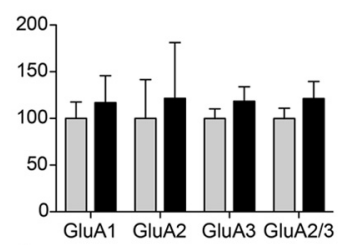

G

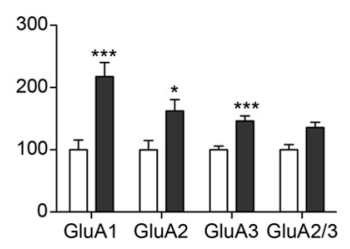

Figure 5. Kal knock-down in the NAc core prevents cocaine-induced increases in AMPAR subunit surface expression on WD14.A, Experimental time line. For all rats, one hemisphere was used for spine analysis (Fig. 4) and the other hemisphere was used for the AMPAR subunit analysis shown here. $\boldsymbol{B}-\boldsymbol{G}$, Cell surface levels (left panels) and intracellular levels (right panels) of AMPAR subunits measured using a $B S^{3}$ protein crosslinking assay and immunoblotting. $\boldsymbol{B}$, Surface-expressed GluA1 and GluA2 increased after repeated cocaine injections (GFP/Sal, $n=$ 10; GFP/Coc, $n=9$ ). C, Compared with GFP/Coc rats, surface GluA1 was significantly lower in rats that received shKal before repeated cocaine injections (GFP/Coc, $n=8$; shKal/Coc, $n=9$ ). There were also trends toward relatively lower surface expression of other subunits in $\mathrm{ShKal} / \mathrm{Coc}$ rats. D, Knock-down of Kal before repeated saline injections decreased surface GluA2/3 compared with GFP/Sal rats (GFP/Sal, $n=11$; shKal/Sal, $n=11)$. $E$, After cocaine treatment, there was a reduction in intracellular GluA3 levels in GFP/Coc compared with GFP/Sal rats. $\boldsymbol{F}$, № differences in intracellular AMPAR subunit levels were observed between GFP/Coc and shKal/ Cocrats. G, Knock-down of Kal before repeated saline injections produced a marked intracellular accumulation of GluA1-3 $\left({ }^{*} p<0.05,{ }^{* *} p<0.01,{ }^{* * *} p<0.001\right)$.

zation (main effect of viral treatment: $F_{(1,27)}=0.24$, n.s.; main effect of days: $F_{(1,27)}=28.13, p<0.001$; viral treatment $\times$ days interaction: $F_{(1,27)}=0.45$, n.s.). On WD7, jugular catheters were implanted to enable cocaine self-administration. On WD14, when locomotor sensitization was maintained in shKal/Coc rats but neither AMPAR nor spine upregulation had occurred (Figs. 4, 5, 6), we began cocaine self-administration training $(2 \mathrm{~h} / \mathrm{d}$ for $10 \mathrm{~d})$. A low dose of cocaine $(0.15 \mathrm{mg} / \mathrm{kg})$ was selected based on preliminary studies (data not shown). This dose was sufficient for cocaine preexposed animals to readily acquire cocaine self-administration because cocaine already has an elevated incentive value for these animals, whereas it was subthreshold for saline-pretreated or drug-naive animals, who therefore took longer to acquire stable self-administration behavior.

We found that pretreatment (saline vs cocaine injections) modified cocaine intake across days (Fig. 7C; main effect of pretreatment: $F_{(3,47)}=7.66, p<0.001$; main effect of days: $F_{(9,423)}=8.30, p<$ 0.001 ; interaction between days and pretreatment: $F_{(27,423)}=1.71$, $p<0.05)$. Specifically, GFP/Coc rats did not differ significantly from other groups on days $1-3$, but they gradually increased their intake on subsequent days (GFP/Coc vs GFP/Sal: ${ }^{*} p<0.05,{ }^{* *} p<0.01$, ${ }^{* * *} p<0.001$; GFP/Coc vs ShKal/Coc: ${ }^{\#} p<0.05,{ }^{\# \#} p<0.01,{ }^{\# \# \#} p<$ $0.001 ; \mathrm{GFP} / \mathrm{Coc}$ vs ShKal/Sal: ${ }^{\&} p<0.05,{ }^{\& \&} p<0.01,{ }^{\& \& \&} p<$

A

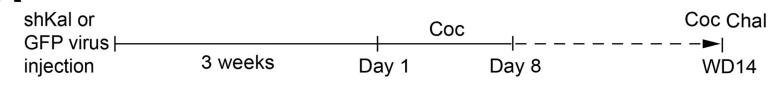

B
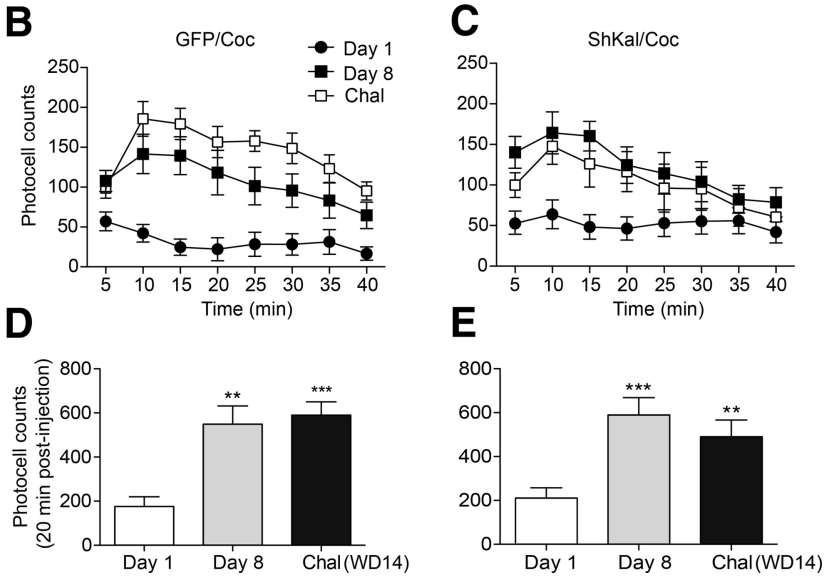

Figure 6. Kal knock-down does not prevent the development or maintenance of locomotor sensitization. $\boldsymbol{A}$, Experimental time line. $\boldsymbol{B}-\boldsymbol{E}$, Locomotor sensitization was assessed by comparing photocell counts on injection days 1 and 8 and after a challenge injection on WD14. Data are presented as mean number of beam breaks per 5 min interval during the first 40 min after cocaine injection $(\boldsymbol{B}, \boldsymbol{C})$ and total beam breaks summed over $20 \mathrm{~min}$ after injection $(\boldsymbol{D}, \boldsymbol{E})$. In both $\mathrm{GFP} / \mathrm{Coc}$ and shKal/Coc rats, the locomotor response to cocaine was markedly greater on day 8 than day 1 and sensitization was expressed at approximately the same level on day 8 and WD14. The cocaine dose was $15 \mathrm{mg} / \mathrm{kg}$ on all days (GFP/Coc, $n=8$; ShKal/Coc, $n=9$; ${ }^{*} p<0.05$, ${ }^{* *} p<0.01,{ }^{* * *} p<0.001$ vs day 1$)$.

0.001), whereas the intake of shKal/Coc animals plateaued at the same level reached by the GFP/Sal group. A comparison was also made for active versus inactive nose-poke responses (Fig. 7D-G). Pretreatment modified responding in the active hole, with GFP/Coc rats consistently showing higher responding than all other groups [main effect of pretreatment: $F_{(3,47)}=5.60, p<0.01$; main effect of days: $F_{(9,423)}=3.37, p<0.001$; interaction between days and pretreatment: $F_{(27,423)}=0.71, p=0.86$, n.s.; GFP/Coc vs GFP/Sal: $p<$ 0.01; GFP/Coc vs ShKal/Sal: $p<0.05$; GFP/Coc vs ShKal/Coc: $p<$ $0.01]$. Pretreatment did not modify responding in the inactive hole (main effect of pretreatment: $F_{(3,47)}=0.30, p=0.83$, n.s.; main effect of days: $F_{(9,423)}=7.39, p<0.001$; interaction between days and pretreatment: $F_{(27,423)}=1.03, p=0.43$, n.s.). Therefore, with respect to both infusions and nose pokes, shKal/Coc rats resembled GFP/ Coc rats during the initial training days, but came to resemble GFP/ Sal and shKal/Sal rats over subsequent days. We interpret these data to indicate that, based on their prior intraperitoneal cocaine injection experience, the shKal/Coc rats "recognized" cocaine and rapidly learned the operant response. However, compared with the GFP/ Coc rats, the shKal/Coc rats took fewer infusions over the remaining days of training, reflecting lower motivation for cocaine.

After completion of the self-administration experiment, we measured Kal immunostaining in the NAc. Kal expression in transfected cells from shKal/Coc rats was reduced by $43 \%$ compared with nontransfected cells, verifying that shKal virus was stably expressed throughout our experiment (data not shown).

\section{Sucrose self-administration is not impaired by Kal knock-down}

To rule out the possibility that Kal knock-down caused a general impairment of reward-seeking behavior, we determined the effect of shKal on self-administration of a natural reward, sucrose. Two weeks after injection of GFP or shKal virus into the NAc core, rats were tested for self-administration of sucrose pel- 
A

$\begin{array}{llll}\text { shKal or } & 2 \text { weeks } & \text { Sal or Coc } & \text { I.V. surgery } \\ \text { GFP virus } & \text { Dequisition of Coc SA (10 days) } \\ \text { injection } & \text { Day } 1 & \text { Day } 8 & \text { WD7 }\end{array}$

B

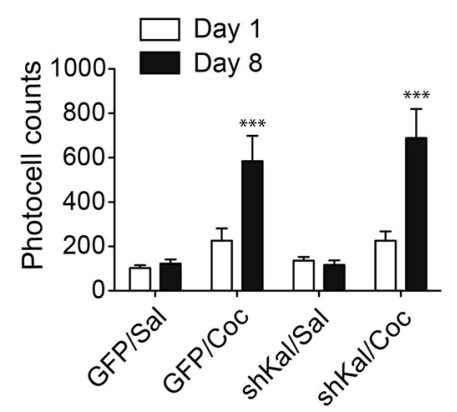

D

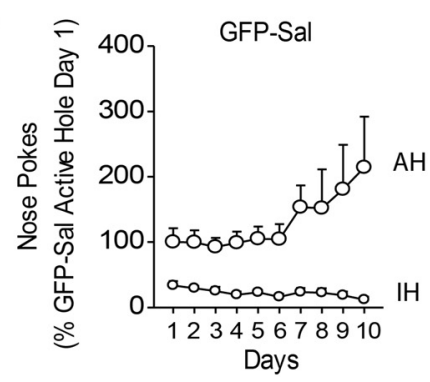

$\mathbf{F}$

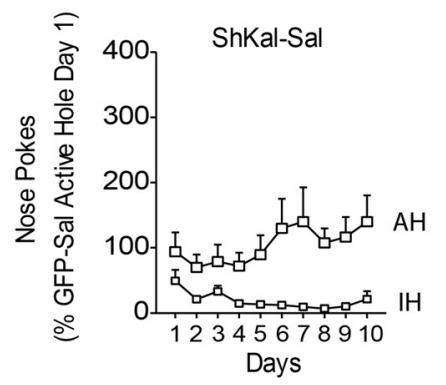

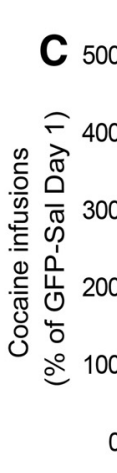

E

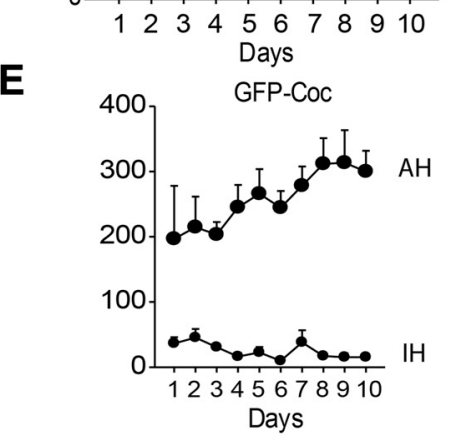

G

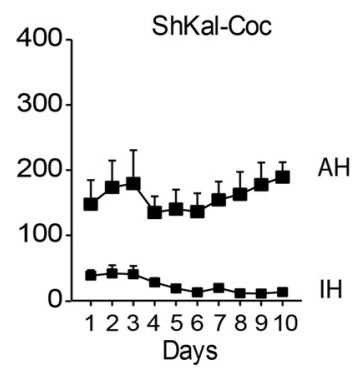

Figure 7. Incentive sensitization, measured as rate of acquisition of cocaine self-administration (SA), is impaired by Kal knockdown. $\boldsymbol{A}$, Experimental time line. After virus injection into the NAc core, followed by repeated saline or cocaine injections, rats were tested for self-administration of intravenous (I.V.) cocaine ( $0.15 \mathrm{mg} / \mathrm{kg}$ per infusion) for $2 \mathrm{~h} / \mathrm{d}$ on 10 consecutive days. $\boldsymbol{B}$, Locomotor activity in the four treatment groups used for cocaine $S A$ acquisition tests. Cocaine pretreatment produced a sensitized locomotor response in both GFP/Coc and shKal/Coc groups, whereas saline pretreatment did not alter locomotor responding (GFP/Sal, $n=$ $\left.12 ; \mathrm{GFP} / \mathrm{Coc}, n=14 ; \mathrm{shKal} / \mathrm{Sal}, n=9 ; \mathrm{shKal} / \mathrm{Coc}, n=15 ;{ }^{*} p<0.05\right)$. C, The number of infusions was normalized to the average of day 1 infusions of the GFP/Sal group (GFP/Sal, $n=12 ; \mathrm{GFP} / \mathrm{Coc}, n=16$; shKal/Sal, $n=8$; shKal/Coc, $n=15$ ). Normalization was required because data are combined from two separate experiments. GFP/Coc and shKal/Coc rats exhibited similar levels of cocaine intake on the first three days. However, GFP/Coc rats gradually increased intake on subsequent days, whereas shKal/Coc animals did not (GFP/Coc vs GFP/Sal: ${ }^{*} p<0.05,{ }^{* *} p<0.01,{ }^{* * *} p<0.001 ;$ GFP/Coc vs ShKal/Coc: ${ }^{*} p<0.05,{ }^{\# \#} p<0.01$, ${ }^{\# \# \#} p<0.001 ;$ GFP/Coc vs ShKal/Sal: $\left.{ }^{\&} p<0.05,{ }^{\&} \& p<0.01,{ }^{\& \& \&}<<0.001\right)$. $\boldsymbol{D}-\mathbf{G}$, The number of nose-poke responses in the active hole $(\mathrm{AH})$ and inactive hole $(\mathrm{IH})$ were compared across groups. The raw values for both $\mathrm{AH}$ and $\mathrm{IH}$ responses were normalized to the average of day $1 \mathrm{AH}$ responses of the GFP/Sal group. All four groups exhibited preference for the AH, although the GFP/COC group had significantly more $\mathrm{AH}$ responses. The number of infusions is not necessarily equivalent to the number of $\mathrm{AH}$ responses due to time-out periods included to prevent overdose.

lets for $2 \mathrm{~h} / \mathrm{d}$ on 9 consecutive days (Fig. $8 A$ ). Viral treatment did not modify sucrose intake across days (Fig. $8 B$; main effect of viral treatment: $F_{(1,18)}=3.13$, n.s.; main effect of days: $F_{(8,144)}=38.90$, $p<0.001$; interaction between viral treatment and days: $F_{(8,144)}$ $=1.27$, n.s.). Moreover, viral treatment did not modify responding in either the active hole (Fig. 8C,D; main effect of viral treatment: $F_{(1,18)}=2.60$, n.s.; main effect of days: $F_{(8,144)}=12.72, p<$ 0.001 ; interaction between viral treatment and days: $F_{(8,144)}=$ 1.40 , n.s.) or the inactive hole (main effect of viral treatment: $F_{(1,18)}$ $=1.05$, n.s.; main effect of days: $F_{(8,144)}=24.92, p<0.001$; interac- tion between viral treatment and days: $F_{(8,144)}=0.58$, n.s.). These data demonstrate that Kal knock-down does not affect the process of learning to seek natural rewards. Consistent with a lack of dependence on Kal for acquisition of sucrose selfadministration, sucrose self-administration did not increase spine density in the NAc (Crombag et al., 2005).

\section{Discussion}

Studies in cultured neurons have shown that Kal-7 is required for activity-dependent increases in AMPAR transmission and spine size (Xie et al., 2007; Penzes and Jones, 2008; Ma et al., 2011), making it an intriguing candidate for mediating cocaine-induced AMPAR and spine plasticity. To explore this idea, we examined Kal-7 signaling, AMPAR surface expression, and dendritic spine density/morphology on WD14 after repeated injections of cocaine or saline. Our results demonstrate activation of the Kal-7-Rac1PAK signaling cascade in the NAc of cocaine-sensitized rats and show that this is necessary for upregulation of both AMPAR surface expression and dendritic spine density. This provides the first evidence for mechanistic coupling of AMPAR and spine plasticity after cocaine exposure. Furthermore, by knocking down Kal-7 in the NAc before repeated cocaine exposure, we show that preventing cocaine-induced increases in AMPAR surface expression and spine density is associated with impairment of incentive sensitization but not locomotor sensitization. These results are the first to demonstrate that these two manifestations of behavioral sensitization involve divergent cellular mechanisms and also the first to demonstrate an association between excitatory synaptic transmission and incentive sensitization.

\section{Repeated cocaine injections persistently} increase Kal-7 signaling in the NAc

Prior studies have found increased levels of Kal-7 protein and mRNA in the NAc $24 \mathrm{~h}$ after discontinuing repeated cocaine injections (Kiraly et al., 2010; Mains et al., 2011; Ma et al., 2012). Our results in the NAc of cocaine-sensitized rats show that Kal-7 protein remains elevated after $14 \mathrm{~d}$ of withdrawal. In addition, we demonstrate that elevation of Kal-7 levels in the NAc of cocaine-sensitized animals is associated with activation of its downstream effectors Rac1 and PAK. Increased Rac1-PAK signaling is likely due to the observed increase in Kal-7 protein rather than to altered phosphorylation of Kal-7, because no phosphorylation signal was detected in the NAc of either saline- or cocaine-treated groups when the majority of Kal-7 protein was immunoprecipitated and analyzed. 

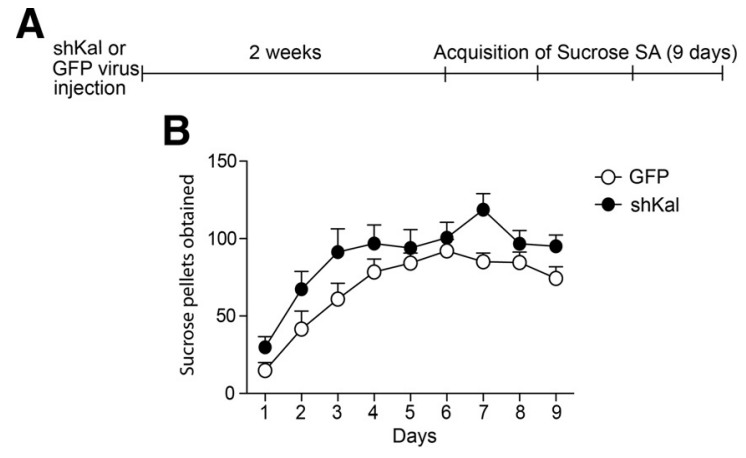

C
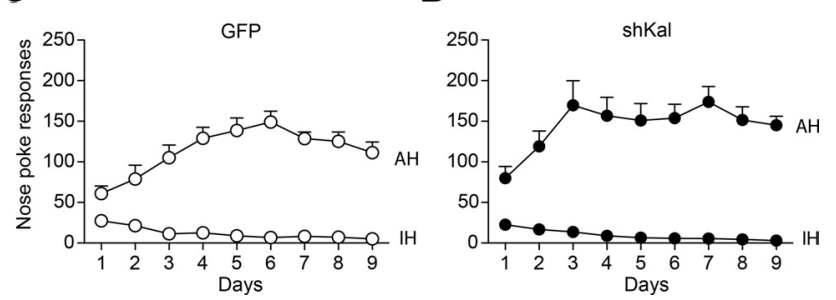

Figure 8. Sucrose self-administration $(S A)$ is not impaired by Kal knock-down. $\boldsymbol{A}$, Experimental time line. GFP or shKal viruses were injected into the NAc core. Two weeks after virus injection, rats were tested for self-administration of sucrose pellets for $2 \mathrm{~h} / \mathrm{d}$ on 9 consecutive days. $\boldsymbol{B}$, The number of sucrose pellets obtained was similar for GFP and shKal groups. $\boldsymbol{C}, \boldsymbol{D}$, The number of nose-poke responses in the active hole ( $\mathrm{AH}$ ) and inactive hole (IH) did not differ significantly between groups.

\section{Kal-7 is required for cocaine-induced AMPAR and spine plasticity}

To study the functional significance of increased Kal-7 signaling, a lentiviral vector expressing Kalirin shRNA was injected into the NAc core before repeated cocaine injections. This treatment, which reduced Kal expression in the NAc by $\sim 50 \%$, prevented the cocaine-induced increases in both AMPAR surface expression and spine density that are otherwise evident on WD14.

Our results provide the first demonstration that Kal-7 signaling regulates AMPAR transmission in the intact brain. Interestingly, the AMPAR subunits affected depended on the treatment group. When Kal knock-down occurred before repeated cocaine treatment, it prevented the increase in cell surface GluA1 and GluA2 that normally occurs in cocaine-sensitized rats. However, in rats that received repeated saline injections, Kal knock-down decreased GluA2/3 surface expression. One interpretation of these results is suggested by an influential model positing that GluA2A3-containing receptors constitutively cycle from intracellular stores to the membrane surface, whereas GluA1A2containing receptors are inserted into the synapse in an activity-dependent manner (Malinow, 2003). It is possible that, under conditions of basal neuronal activity (saline group), Kal preferentially regulates constitutively cycling GluA2A3 receptors. However, once cocaine has been administered and synaptic activity is altered, we speculate that GluA1A2 receptors become the more active player and are therefore more responsive to Kal knock-down.

In cultured cortical neurons, the Kal-7-dependent increase in GluA1 synaptic insertion depends on actin polymerization (Xie et al., 2007). Interestingly, actin polymerization is increased in the rat NAc on WD21 from repeated cocaine injections (Toda et al., 2006). It is possible that actin polymerization is increased due to the observed elevation of Kal-7 levels and is functionally related to increased AMPAR surface expression during cocaine withdrawal. We speculate that the interaction of Kal-7 with the NR2B subunit (Kiraly et al., 2011a) is important for cocaineinduced AMPAR insertion, based on evidence that this insertion occurs at NR2B-containing silent synapses in the NAc during cocaine withdrawal (Huang et al., 2009).

Turning to spine density, our observation that Kal-7 knockdown in the NAc prevented cocaine exposure from increasing spine density is consistent with prior results in Kal-7 knock-out mice (Kiraly et al., 2010). However, although these results suggest that activation of Kal-7/Rac1/PAK signaling is linked to increased spine density, Dietz et al. (2012) found a different relationship between Racl signaling and cocaine-induced spine plasticity in the NAc. A possible explanation is that they examined Racl activity immediately after a challenge injection of cocaine, whereas our experiments were performed after $14 \mathrm{~d}$ of withdrawal.

Although Kal knock-down prevented cocaine-induced increases in spine density, it had no effect on spine density in salinetreated animals. Therefore, Kal may not play an indispensable role in maintenance of basal spine levels; perhaps the loss of Kal function can be compensated by other GEFs. Similarly, indistinguishable spine density in the NAc was found when comparing wild-type and Kal7 knock-out mice under basal conditions (Kiraly et al., 2010; but see Ma et al., 2012 for different results in organotypic slice cultures).

Changes in spines and excitatory synaptic transmission are often coupled during synaptic plasticity (Holtmaat and Svoboda, 2009), but whether this applied to AMPAR and spine plasticity during cocaine withdrawal was unknown before our study. Identifying Kal-7 as a mediator common to both adaptations enabled us to explore their functional significance (see next section). However, although activation of Kal-7 is required for both AMPAR and spine plasticity, the downstream pathways involved in each response may be divergent because increased spine density can be detected as early as $30 \mathrm{~min}$ after discontinuing repeated cocaine injections (Kiraly et al., 2010), whereas AMPAR upregulation requires more than a day to develop (Boudreau and Wolf, 2005; Kourrich et al., 2007).

\section{Increased Kal-7 signaling mediates incentive sensitization to cocaine}

Locomotor sensitization is the most commonly used measure of behavioral sensitization to cocaine. Although it is accompanied by increased AMPAR surface expression and increased spine density, both adaptations can be dissociated from locomotor sensitization either temporally or using molecular manipulations (Singer et al., 2009; Russo et al., 2010; Wolf and Ferrario, 2010). Indeed, our results show that Kal-7 knock-down impairs AMPAR and spine plasticity, but not locomotor sensitization. More work is required to understand this dissociation because some results implicate AMPAR transmission in expression of locomotor sensitization (Pierce et al., 1996), but our results could indicate that cocaine's dopamine-enhancing effects are of paramount importance for locomotor sensitization. It should be noted that the present study, as well as all AMPAR and spine studies cited in the Introduction (with the exception of Wissman et al., 2011), were conducted in male rats. The latter study, which compared the sexes, found no correlation between locomotor sensitization and spine density in male rats, consistent with our results, whereas a correlation was found in female rats.

Interestingly, Kal-7 knock-out mice, which do not exhibit cocaine-induced increases in spine density, exhibit enhanced locomotor sensitization (Kiraly et al., 2010). We did not observe enhanced sensitization, perhaps because we knocked down Kal 
specifically in the NAc during adulthood. In the prior study (Kiraly et al., 2010), there was the potential for developmental adaptations or changes in Kal-7 signaling in other brain regions due to its constitutive deletion.

Psychostimulant pretreatment enhances learning about drugs and drug-related cues and willingness to work for them (Vezina, 2004). These are potential manifestations of incentive sensitization. With the exception of results in genetically modified animals, all studies support a positive correlation between the level of excitatory transmission in the NAc and the motivation to seek cocaine (Wolf and Ferrario, 2010). Therefore, we hypothesized that the cocaine-induced, Kal-7-dependent increases in surface AMPARs and spines strengthen synaptic connections onto NAc neurons and thereby elicit incentive sensitization. Indeed, our results clearly demonstrate that knocking down Kal-7 signaling in the NAc core reduces incentive sensitization, measured as the ability of cocaine preexposure to facilitate self-administration of a low dose of cocaine. Additional studies will be required to determine whether incentive sensitization requires increases in both surface AMPAR levels and spine density or if one is more critical.

Other studies have found a relationship between increased NAc spine density and associative drug conditioning. Therefore, Kal-7 knock-out mice, which do not exhibit cocaine-induced increases in spine density, show impaired conditioned place preference (Kiraly et al., 2010). Conversely, Marie et al. (2012) found a correlation between the magnitude of conditioned place preference and the increase in NAc spine density. Finally, resonating closely with our results, Singer et al. (2009) found that repeated amphetamine exposure increases spine density in the NAc only if the amphetamine regimen leads to conditioned hyperactivity, not if the regimen leads to locomotor sensitization in the absence of conditioned hyperactivity. One interpretation is that increased spine density in these studies reflects acquisition of incentive properties by the drug context (a form of incentive learning).

The original formulation of the incentive sensitization hypothesis of addiction suggested that common neuroadaptations, in the mesocorticolimbic dopamine system and others, enable sensitization of motor activating and incentive motivational effects (Robinson and Berridge, 1993). Indeed, there is strong evidence for overlapping mechanisms (Norrholm et al., 2003; Vezina, 2004; Taylor et al., 2007). Our results are not in opposition to these findings; rather, they indicate that additional Kal-7-dependent adaptations must occur to enable incentive sensitization.

In conclusion, these results identify Kal-7 as an essential link between the mechanisms underlying cocaine-induced structural and functional plasticity. Furthermore, they demonstrate that these Kal-7-dependent adaptations are required for sensitization of the incentive-motivational properties of cocaine but not for sensitization of its locomotor-activating properties.

\section{References}

Boudreau AC, Wolf ME (2005) Behavioral sensitization to cocaine is associated with increased AMPA receptor surface expression in the nucleus accumbens. J Neurosci 25:9144-9151. CrossRef Medline

Boudreau AC, Reimers JM, Milovanovic M, Wolf ME (2007) Cell surface AMPA receptors in the rat nucleus accumbens increase during cocaine withdrawal but internalize after cocaine challenge in association with altered activation of mitogen-activated protein kinases. J Neurosci 27: 10621-10635. CrossRef Medline

Boudreau AC, Ferrario CR, Glucksman MJ, Wolf ME (2009) Signaling pathway adaptations and novel protein kinase A substrates related to behavioral sensitization to cocaine. J Neurochem 110:363-377. CrossRef Medline
Boudreau AC, Milovanovic M, Conrad KL, Nelson C, Ferrario CR, Wolf ME (2012) A protein cross-linking assay for measuring cell surface expression of glutamate receptor subunits in the rodent brain after in vivo treatments. Curr Protocols Neurosci, Unit 5.30.1-19. CrossRef Medline

Brown TE, Lee BR, Mu P, Ferguson D, Dietz D, Ohnishi YN, Lin Y, Suska A, Ishikawa M, Huang YH, Shen H, Kalivas PW, Sorg BA, Zukin RS, Nestler EJ, Dong Y, Schlüter OM (2011) A silent synapse-based mechanism for cocaine-induced locomotor sensitization. J Neurosci 31:8163-8174. CrossRef Medline

Cahill ME, Xie Z, Day M, Photowala H, Barbolina MV, Miller CA, Weiss C, Radulovic J, Sweatt JD, Disterhoft JF, Surmeier DJ, Penzes P (2009) Kalirin regulates cortical spine morphogenesis and disease-related behavioral phenotypes. Proc Natl Acad Sci U S A 106:13058-13063. CrossRef Medline

Christoffel DJ, Golden SA, Dumitriu D, Robison AJ, Janssen WG, Ahn HF, Krishnan V, Reyes CM, Han MH, Ables JL, Eisch AJ, Dietz DM, Ferguson D, Neve RL, Greengard P, Kim Y, Morrison JH, Russo SJ (2011) I kinase regulates social defeat stress-induced synaptic and behavioral plasticity. J Neurosci 31:314-321. CrossRef Medline

Conrad KL, Tseng KY, Uejima JL, Reimers JM, Heng LJ, Shaham Y, Marinelli M, Wolf ME (2008) Formation of accumbens GluR2-lacking AMPA receptors mediates incubation of cocaine craving. Nature 454:118-121. CrossRef Medline

Crombag HS, Gorny G, Li Y, Kolb B, Robinson TE (2005) Opposite effects of amphetamine self-administration experience on dendritic spines in the medial and orbital prefrontal cortex. Cereb Cortex 15:341-348. CrossRef Medline

Dietz DM, Sun H, Lobo MK, Cahill ME, Chadwick B, Gao V, Koo JW, MazeiRobison MS, Dias C, Maze I, Damez-Werno D, Dietz KC, Scobie KN, Ferguson D, Christoffel D, Ohnishi Y, Hodes GE, Zheng Y, Neve RL, Hahn KM, Russo SJ, Nestler EJ (2012) Racl is essential in cocaineinduced structural plasticity of nucleus accumbens neurons. Nat Neurosci 15:891-896. CrossRef Medline

Dobi A, Seabold GK, Christensen CH, Bock R, Alvarez VA (2011) Cocaineinduced plasticity in the nucleus accumbens is cell specific and develops without prolonged withdrawal. J Neurosci 31:1895-1904. CrossRef Medline

Dumitriu D, Rodriguez A, Morrison JH (2011) High-throughput, detailed, cell-specific neuroanatomy of dendritic spines using microinjection and confocal microscopy. Nat Protoc 6:1391-1411. CrossRef Medline

Ferrario CR, Gorny G, Crombag HS, Li Y, Kolb B, Robinson TE (2005) Neural and behavioral plasticity associated with the transition from controlled to escalated cocaine use. Biol Psychiatry 58:751-759. CrossRef Medline

Ferrario CR, Li X, Wang X, Reimers JM, Uejima JL, Wolf ME (2010) The role of glutamate receptor redistribution in locomotor sensitization to cocaine. Neuropsychopharmacol 35:818-833. CrossRef Medline

Ghasemzadeh MB, Mueller C, Vasudevan P (2009) Behavioral sensitization to cocaine is associated with increased glutamate receptor trafficking to the postsynaptic density after extended withdrawal period. Neurosci 159: 414-426. CrossRef Medline

Goel A, Jiang B, Xu LW, Song L, Kirkwood A, Lee HK (2006) Cross-modal regulation of synaptic AMPA receptors in primary sensory cortices by visual experience. Nat Neurosci 9:1001-1003. CrossRef Medline

Golden SA, Russo SJ (2012) Mechanisms of psychostimulant-induced structural plasticity. Cold Spring Harb Perspect Med 2:pii:a011957. CrossRef Medline

Hayashi K, Ohshima T, Mikoshiba K (2002) Pak1 is involved in dendrite initiation as a downstream effector of Racl in cortical neurons. Mol Cell Neurosci 20:579-594. CrossRef Medline

Holtmaat A, Svoboda K (2009) Experience-dependent structural synaptic plasticity in the mammalian brain. Nat Rev Neurosci 10:647-658. CrossRef Medline

Horger BA, Shelton K, Schenk S (1990) Pre-exposure sensitizes rats to the rewarding effects of cocaine. Pharmacol Biochem Behav 37:707-711. CrossRef Medline

Huang YH, Lin Y, Mu P, Lee BR, Brown TE, Wayman G, Marie H, Liu W, Yan Z, Sorg BA, Schlüter OM, Zukin RS, Dong Y (2009) In vivo cocaine experience generates silent synapses. Neuron 63:40-47. CrossRef Medline

Kalivas PW, Volkow ND (2005) The neural basis of addiction: a pathology 
of motivation and choice. Am J Psychiatry 162:1403-1413. CrossRef Medline

Kiraly DD, Ma XM, Mazzone CM, Xin X, Mains RE, Eipper BA (2010) Behavioral and morphological responses to cocaine require kalirin7. Biol Psychiatry 68:249-255. CrossRef Medline

Kiraly DD, Lemtiri-Chlieh F, Levine ES, Mains RE, Eipper BA (2011a) Kalirin binds the NR2B subunit of the NMDA receptor, altering its synaptic localization and function. J Neurosci 31:12554-12565. CrossRef Medline

Kiraly DD, Stone KL, Colangelo CM, Abbott T, Wang Y, Mains RE, Eipper BA (2011b) Identification of Kalirin-7 as a potential post-synaptic density signaling hub. J Proteome Res 10:2828-2841. CrossRef Medline

Kourrich S, Rothwell PE, Klug JR, Thomas MJ (2007) Cocaine experience controls bidirectional synaptic plasticity in the nucleus accumbens. J Neurosci 27:7921-7928. CrossRef Medline

Kreis P, Barnier JV (2009) PAK signaling in neuronal physiology. Cell Signal 21:384-393. CrossRef Medline

LaPlant Q, Vialou V, Covington HE 3rd, Dumitriu D, Feng J, Warren BL, Maze I, Dietz DM, Watts EL, Iñiguez SD, Koo JW, Mouzon E, Renthal W, Hollis F, Wang H, Noonan MA, Ren Y, Eisch AJ, Bolaños CA, Kabbaj M, Xiao G, Neve RL, Hurd YL, Oosting RS, Fan G, Morrison JH, Nestler EJ (2010) Dnmt3a regulates emotional behavior and spine plasticity in the nucleus accumbens. Nat Neurosci 13:1137-1143. CrossRef Medline

Lasek AW, Janak PH, He L, Whistler JL, Heberlein U (2007) Downregulation of mu opioid receptor by RNA interference in the ventral tegmental area reduces ethanol consumption in mice. Gene Brain Behav 6:728-735. CrossRef Medline

Li J, Liu N, Lu K, Zhang L, Gu J, Guo F, An S, Zhang L, Zhang L (2012) Cocaine-induced dendritic remodeling occurs in both D1 and D2 dopamine receptor-expressing neurons in the nucleus accumbens. Neurosci Lett 517:118-122. CrossRef Medline

Li Y, Acerbo MJ, Robinson TE (2004) The induction of behavioral sensitization is associated with cocaine-induced structural plasticity in the core (but not shell) of the nucleus accumbens. Eur J Neurosci 20:1647-1654. CrossRef Medline

Lorrain DS, Arnold GM, Vezina P (2000) Previous exposure to amphetamine increases incentive to obtain the drug: long-lasting effects revealed by the progressive ratio schedule. Behav Brain Res 107:9-19. CrossRef Medline

Ma XM (2010) Kalirin-7 is a key player in the formation of excitatory synapses in hippocampal neurons. ScientificWorldJournal 10:1655-1666. CrossRef Medline

Ma XM, Huang JP, Kim EJ, Zhu Q, Kuchel GA, Mains RE, Eipper BA (2011) Kalirin-7, an important component of excitatory synapses, is regulated by estradiol in hippocampal neurons. Hippocampus 21:661-677. CrossRef Medline

Ma XM, Huang JP, Xin X, Yan Y, Mains RE, Eipper BA (2012) A role for Kalirin in the response of rat medium spiny neurons to cocaine. Mol Pharmacol 82:738-745. CrossRef Medline

Mains RE, Kiraly DD, Eipper-Mains JE, Ma XM, Eipper BA (2011) Kalrn promoter usage and isoform expression respond to chronic cocaine exposure. BMC Neurosci 12:20. CrossRef Medline

Malinow R (2003) AMPA receptor trafficking and long-term potentiation. Philos Trans R Soc Lond B Biol Sci 358:707-714. CrossRef Medline

Marie N, Canestrelli C, Noble F (2012) Transfer of neuroplasticity from nucleus accumbens core to shell is required for cocaine reward. PLoS One 7(1):e30241. CrossRef

Martin BJ, Naughton BJ, Thirtamara-Rajamani K, Yoon DJ, Han DD, Devries AC, Gu HH (2011) Dopamine transporter inhibition is necessary for cocaine-induced increases in dendritic spine density in the nucleus accumbens. Synapse 65:490-496. CrossRef Medline

Maze I, Covington HE 3rd, Dietz DM, LaPlant Q, Renthal W, Russo SJ, Mechanic M, Mouzon E, Neve RL, Haggarty SJ, Ren Y, Sampath SC, Hurd YL, Greengard P, Tarakhovsky A, Schaefer A, Nestler EJ (2010) Essential role of the histone methyltransferase G9a in cocaine-induced plasticity. Science 327:213-216. CrossRef Medline

McCutcheon JE, Wang X, Tseng KY, Wolf ME, Marinelli M (2011) Calcium-permeable AMPA receptors are present in nucleus accumbens synapses after long withdrawal from cocaine self-administration but not experimenter-administered cocaine. J Neurosci 31:5737-5743. CrossRef Medline

Mendrek A, Blaha CD, Phillips AG (1998) Pre-exposure of rats to amphet- amine sensitizes self-administration of this drug under a progressive ratio schedule. Psychopharmacology 135:416-422. CrossRef Medline

Meredith GE, Baldo BA, Andrezjewski ME, Kelley AE (2008) The structural basis for mapping behavior onto the ventral striatum and its subdivisions. Brain Struct Funct 213:17-27. CrossRef Medline

Norrholm SD, Bibb JA, Nestler EJ, Ouimet CC, Taylor JR, Greengard P (2003) Cocaine-induced proliferation of dendritic spines in nucleus accumbens is dependent on the activity of cyclin-dependent kinase-5. Neuroscience 116:19-22. CrossRef Medline

Penzes P, Jones KA (2008) Dendritic spine dynamics - a key role for Kalirin-7. Trends Neurosci 31:419-427. CrossRef Medline

Penzes P, Johnson RC, Alam MR, Kambampati V, Mains RE, Eipper BA (2000) An isoform of kalirin, a brain-specific GDP/GTP exchange factor, is enriched in the postsynaptic density fraction. J Biol Chem 275:6395-6403. CrossRef Medline

Pierce RC, Bell K, Duffy P, Kalivas PW (1996) Repeated cocaine augments excitatory amino acid transmission in the nucleus accumbens only in rats having developed behavioral sensitization. J Neurosci 16:1550-1560. Medline

Pulipparacharuvil S, Renthal W, Hale CF, Taniguchi M, Xiao G, Kumar A, Russo SJ, Sikder D, Dewey CM, Davis MM, Greengard P, Nairn AC, Nestler EJ, Cowan CW (2008) Cocaine regulates MEF2 to control synaptic and behavioral plasticity. Neuron 59:621-633. CrossRef Medline

Ren Z, Sun WL, Jiao H, Zhang D, Kong H, Wang X, Xu M (2010) Dopamine D1 and $N$-methyl-D-aspartate receptors and extracellular signalregulated kinase mediate neuronal morphological changes induced by repeated cocaine administration. Neurosci 168:48-60. CrossRef Medline

Robinson TE, Berridge KC (1993) The neural basis of drug craving: an incentive-sensitization theory of addiction. Brain Res Brain Res Rev 18: 247-291. CrossRef Medline

Robinson TE, Berridge KC (2008) The incentive sensitization theory of addiction: some current issues. Philos Trans R Soc Lond B Biol Sci 363: 3137-3146. CrossRef Medline

Robinson TE, Kolb B (1999) Alterations in the morphology of dendrites and dendritic spines in the nucleus accumbens and prefrontal cortex following repeated treatment with amphetamine or cocaine. Eur J Neurosci 11:1598-1604. CrossRef Medline

Robinson TE, Kolb B (2004) Structural plasticity associated with exposure to drugs of abuse. Neuropharmacology 47:33-46. CrossRef Medline

Rodriguez A, Ehlenberger DB, Dickstein DL, Hof PR, Wearne SL (2008) Automated three-dimensional detection and shape classification of dendritic spines from fluorescence microscopy images. PLoS One 3:e1997. CrossRef Medline

Russo SJ, Wilkinson MB, Mazei-Robison MS, Dietz DM, Maze I, Krishnan V, Renthal W, Graham A, Birnbaum SG, Green TA, Robison B, Lesselyong A, Perrotti LI, Bolaños CA, Kumar A, Clark MS, Neumaier JF, Neve RL, Bhakar AL, Barker PA, Nestler EJ (2009) Nuclear factor kappa B signaling regulates neuronal morphology and cocaine reward. J Neurosci 29: 3529-3537. CrossRef Medline

Russo SJ, Dietz DM, Dumitriu D, Morrison JH, Malenka RC, Nestler EJ (2010) The addicted synapse: mechanisms of synaptic and structural plasticity in nucleus accumbes. Trends Neurosci 33:267-276. CrossRef Medline

Schenk S, Partridge B (2000) Sensitization to cocaine's reinforcing effects produced by various cocaine pretreatment regimens in rats. Pharmacol Biochem Behav 66:765-770. CrossRef Medline

Schierberl K, Hao J, Tropea TF, Ra S, Giordano TP, Xu Q, Garraway SM, Hofmann F, Moosmang S, Striessnig J, Inturrisi CE, Rajadhyaksha AM (2011) $\mathrm{Ca}_{\mathrm{v}} 1.2$ L-type $\mathrm{Ca}^{+2}$ channels mediate cocaine-induced GluA1 trafficking in the nucleus accumbens, a long-term adaptation dependent on ventral tegmental area $\mathrm{Ca}_{\mathrm{v}} 1.3$ channels. J Neurosci 31:13562-13575. CrossRef Medline

Schumann J, Yaka R (2009) Prolonged withdrawal from repeated noncontingent cocaine exposure increases NMDA receptor expression and ERK activity in the nucleus accumbens. J Neurosci 29:6955-6963. CrossRef Medline

Singer BF, Tanabe LM, Gorny G, Jake-Matthews C, Li Y, Kolb B, Vezina P (2009) Amphetamine-induced changes in dendritic morphology in rat forebrain correspond to associative drug conditioning rather than nonassociative drug sensitization. Biol Psychiatry 65:835-840. CrossRef Medline

Taylor JR, Lynch WJ, Sanchez H, Olausson P, Nestler EJ, Bibb JA (2007) 
Inhibition of CDK5 in the nucleus accumbens enhances the locomotoractivating and incentive-motivational effects of cocaine. Proc Natl Acad Sci U S A 104:4147-4152. CrossRef Medline

Toda S, Shen HW, Peters J, Cagle S, Kalivas PW (2006) Cocaine increases actin cycling: effects in the reinstatement model of drug seeking. J Neurosci 26:1579-1587. CrossRef Medline

Vezina P (2004) Sensitization of midbrain dopamine neuron reactivity and the self-administration of psychomotor stimulant drugs. Neurosci Biobehav Rev 27:827-839. CrossRef Medline

Wissman AM, McCollum AF, Huang GZ, Nikrodhanond AA, Woolley CS (2011) Sex differences and effects of cocaine on excitatory synapses in the nucleus accumbens. Neuropharmacology 61:217-227. CrossRef Medline Wolf ME, Ferrario CR (2010) AMPA receptor plasticity in the nucleus ac- cumbens after repeated exposure to cocaine. Neurosci Biobehav Rev 35: 185-211. CrossRef Medline

Wyvell CL, Berridge KC (2001) Incentive sensitization by previous amphetamine exposure: Increased cue-triggered "wanting" for sucrose reward. J Neurosci 21:7831-7840. Medline

Xie Z, Srivastava DP, Photowala H, Kai L, Cahill ME, Woolfrey KM, Shum CY, Surmeier DJ, Penzes P (2007) Kalirin-7 controls activity-dependent structural and functional plasticity of dendritic spines. Neuron 56:640-656. CrossRef Medline

Zhang L, Li J, Liu N, Wang B, Gu J, Zhang M, Zhou Z, Jiang Y, Zhang L, Zhang L (2012) Signaling via dopamine D1 and D3 receptors oppositely regulates cocaine-induced structural remodeling of dendrites and spines. Neurosignals 20:15-34. CrossRef Medline 